\title{
MAPPING BUILT-UP AREAS USING TWO BAND RATIO ON LANDSAT IMAGERY OF ACCRA IN GHANA FROM 1980 TO 2017
}

\author{
TwUMASI, N. Y. D. $.^{1,2^{*}}-$ SHAO, Z. ${ }^{1}-$ ALTAN, O. ${ }^{3}$ \\ ${ }^{1}$ State Key Laboratory of Information Engineering in Surveying, Mapping and Remote Sensing, \\ Wuhan University, 129 Luoyu Road, Wuhan 430079, China \\ (e-mail: NanaTwumasi@whu.edu.cn; shaozhenfeng@whu.edu.cn; phone +86-158-2718-8114) \\ ${ }^{2}$ Civil Engineering Department, Wa Polytechnic, Box 553, Wa, Ghana \\ (e-mail: bnydt45.ny@gmail.com; phone +233-024-943-9043) \\ ${ }^{3}$ Department of Geomatics, Istanbul Technical University, 36626 Istanbul, Turkey \\ (e-mail: oaltan@itu.edu.tr; phone: +90-532-446-4409) \\ *Corresponding author \\ e-mail: NanaTwumasi@whu.edu.cn; phone: + 86-131-7202-8873 \\ (Received 28 $8^{\text {th }}$ May 2019; accepted 28 ${ }^{\text {th }}$ Aug 2019)
}

\begin{abstract}
Lack of historical land cover and urban growth governance structure makes spatial planning within the economic capitals of developing countries difficult. Monitoring urban built-up growth with insitu methods is complicated. In this paper, long-term Landsat archive is utilised to map the built-up areas of Accra, the economic capital of Ghana, in Africa. Simple two band ratio and band combination is coupled with historic Google Earth imagery to monitor built-up dynamics from 1980-2017. A 10-year period was sub-divided into three parts each; early period, mid period and late period - for analysis. Maximum Likelihood classifier was used for the classification within the ENVI environment. The results show $11.90 \%$ as the highest and $4.63 \%$ as the lowest built-up growth rates between 2001-2005 and 19962000 respectively. Annual loss of non-built-up areas was $1.31 \%$, and $48.57 \%$ over the entire study period. Water bodies lost $0.08 \%$ annually but $3.1 \%$ over the 37 -year period. Highest and lowest overall accuracy were $87.18 \%$ and $81.31 \%$ respectively, with an average kappa coefficient of 0.7618 . Gain in the built-up area was $1676.69 \mathrm{~km}^{2}$ but non-built up areas lost $1576.10 \mathrm{~km}^{2}$ while water bodies lost $100.60 \mathrm{~km}^{2}$. Results will be of interest to spatial planners, policy makers and land administrators.

Keywords: long term images, urbanization, band index, band combination, urban change rate, urban growth rate
\end{abstract}

\section{Introduction}

Rapid urbanisation poses challenges to the United Nations sustainable goals (GilesCorti et al., 2017), because challenges still exists in finding both temporal and spatial change information over a long period (Li et al., 2018). Ghana, like other developing countries face these challenges as well (The World Bank Group, 2015). However, there are very few studies done on the economic capitals, where most of the urbanisation takes place. These challenges are further worsened by low and sometimes nonavailability of readily available long-term, urban growth governance structures, land cover maps, census data and high population projection ambiguity (Satterthwaite, 2010). Sometimes the data used is erroneous due to lack of size estimates and growth (Potts, 2012; Songsore, 2010). Gathering in-situ datasets to monitor urban growth in these countries is difficult, hence most developing countries like Ghana have turned to remote sensing for urban expansion studies and densification analysis (Potts, 2012). The use of long-term remote sensing datasets offers a full analysis which is believed to provide decision makers information for informed commitments on economic policy 
drafting and spatial planning, to realise a translated impact of government economic policies, as there is a direct relation between population growth, urbanisation, infrastructure deficits and Gross Dometic Product (GDP).

A tentative attempt by (Osei et al., 2013) used only two-year imagery for the study on Accra, which is inadequate for an in-depth analysis. Previous studies have mapped the urban expansion extent and its monitoring for various applications using varied approaches; urbanisation and urban growth (Li and Yeh, 2000; Li, et al., 2015; Mohammady et al., 2013; Cobbinah and Niminga-Beka, 2017; Mu et al., 2006), urban expansion and urban sprawl (Angel et al., 2011; Yin et al., 2011; Ghosh et al., 2017), urban landcover change (Seto et al., 2000; Defries et al., 2010; Yang et al., 2014), all have used impervious surface extraction as a part for their study and analysis (Chester and Gibbons, 1996). A few have scrutinised spatial patterns of urban distribution and expansion with buffer zones in different directions (Li et al., 2016). Impervious Surface Areas (ISA) extraction, has mostly been done with high resolution imagery (HRI) due to accuracy issues. Spatial resolution becomes very important depending on the impervious characteristic under study (Sobrino et al., 2012).

Various studies (Guo et al., 2015; Yao et al., 2018; Sharma et al., 2016) and (Kuang et al., 2014), have proposed ISA extraction improvements using datasets such as Defense Meteorological Satellite Program-Operational Linescan System (DMSP-OLS), Quick Bird, Landsat, Visible Infrared Imaging Radiometer Suite-Day/Night Band (VIIRS-DNB), Moderate Resolution Imaging Spectroradiometer (MODIS), IKONOS and Advanced Spaceborne Thermal Emission and Reflection Radiometer (ASTER). In their proposed methods of multiresolution segmentation and canny algorithms, object layers were created first before extraction by spectrum, shape, size, texture, topology and context characteristics of the object. Noises were removed and the local singularity issue as well as the pepper and salt phenomenon were solved. However, the use of HRI and other data that are costly makes it difficult to replicate their methods especially over large regions in developing countries due to lack of research funds.

Again, the cost of HRI is a great challenge in Ghana which hinders urban studies research. These HRI also do not have the long-term advantage of more than two decades of data. This is a challenge for those involved in historical urban studies. As such urban feature extraction for analysis and planning sustainability is difficult. Landsat Thematic Mapper/Enhanced Thematic Mapper Plus/Operational Land Imager (TM/ETM + /OLI) data archive provide a solution to this hurdle, and are currently freely available with a global coverage. Most of these previous studies applied complex mathematical equations (Varshney and Rajesh, 2014) of spectral indices, sometimes combining two or more of these indices (Xiang et al., 2016), which are sometimes difficult to replicate. Also these applications were done on quite smaller areas and the effect of these methods is not fully appreciated over very large areas. Band ratios and band combinations can be useful in any scale of area for classification. Most important is the validating of the classification results or the algorithm. Long-term ground truth data is difficult to come by or in most cases impossible to acquire if it did not exist already. In this discussion we used the historical Google Earth (GE) map facility to obtain the ground truth. Landsat $(4,5,7$, and 8 ) imagery is used to extract the built-up areas for change dynamics analysis.

The main aims of this paper are; to do a built up analysis of the growth rate, growth change and the spatial area coverage of Greater Accra Region, the economic capital of Ghana, and, to provide a long-term base data for analysis in a long period spatial planning 
for the Accra city planners. These examinations will be done using a two band ratio and Maximum Likelihood (ML) classifier. Most band ratio applications are coupled with multisource data, especially for lithological applications. In this study two band ratios solely applied to a single source data. Study is important because, analyses presented here can give an indication of the future impacts associated with urban built-up dynamics. Lessons drawn from happenings and the implemented solutions to them. For instance, most developed countries have turned to high rise buildings to solve the accommodation problem of the ever increasing urban population. These high rise buildings have caused an increase in surface temperatures at the heart of the cities (Giridharan, et al., 2004; J. Lu et al., 2007). Solutions to this problem have been suggested by (Kolokotroni et al., 2018). These lessons can inform the Ghana government not to commit the same mistakes of the advanced countries. This study is also vital for the development of sustainable policies to improve the adverse consequences of urbanization for sustainable urban development (Estoque and Murayama, 2015; Arsanjani et al., 2013).

\section{Materials and methods}

\section{Study setting}

The economic capital of most developing countries has similar traits. Most buildings within the Metropolitan are high rising and concentrated within the heart of the metropolis. This quick urban advancement comes with a constant congregation of population and an intense industrialisation (Senanayake et al., 2013) which has created its own environmental problems (Hettiarachchi et al., 2014). Most roads are paved, except some residential roads for newly developing estates. These characteristics are also observed in the study area. Accra had a population of 1.7 million as of 2010 (Ghana Statistical Service, 2014) and estimated to be 2.27 million by 2018. The total size area of Greater Accra Region is $3245 \mathrm{~km}^{2}$, map of which is shown in Figure 1.

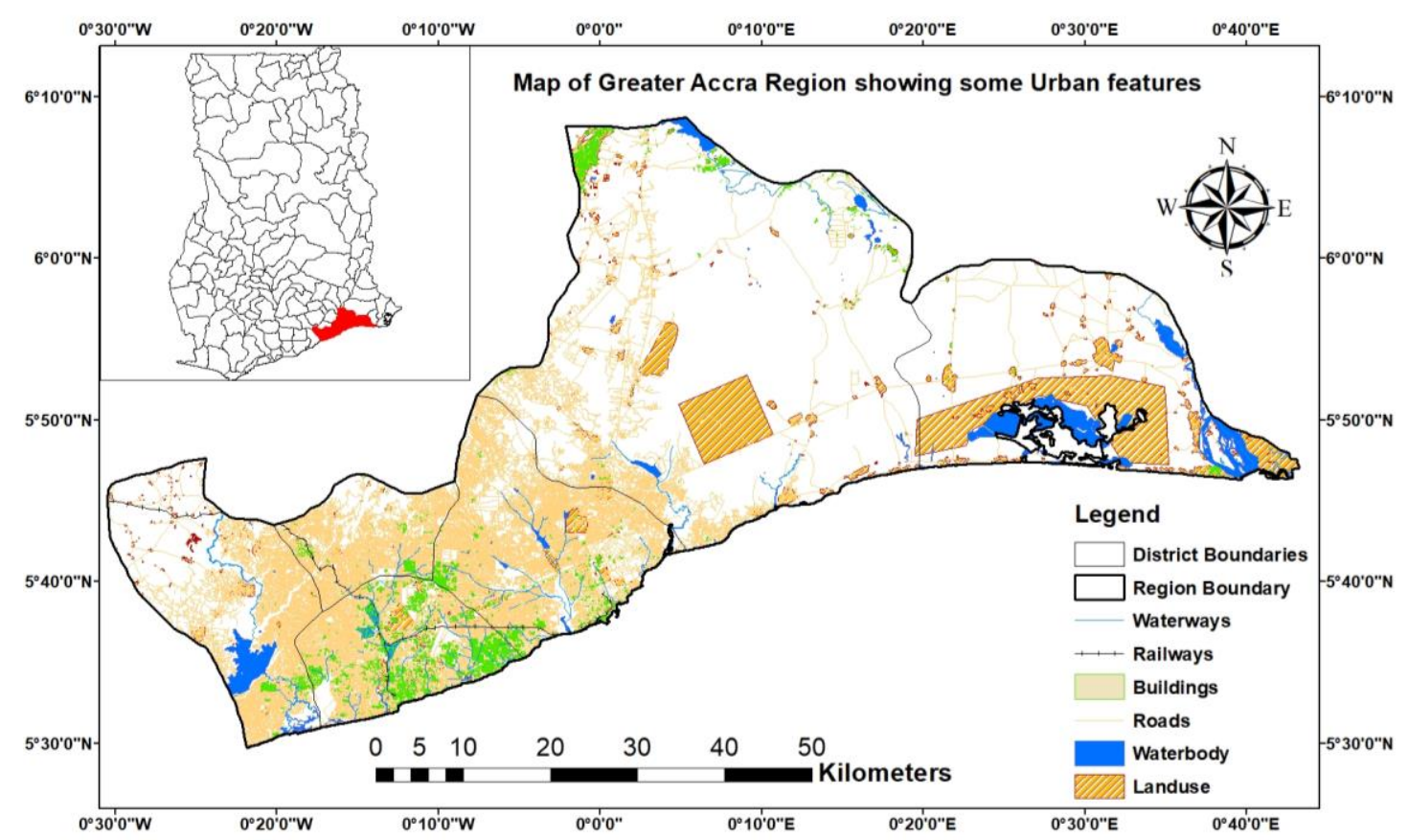

Figure 1. Map of Greater Accra Region (insert: Ghana, study area shown in red) 


\section{Dataset}

We used Landsat imagery over a period of thirty-seven (37) years (1980-2017). However, one imagery before 1980 was obtained to provide a before-baseline comparison. The structure of Landsat Level-1 products ensures the provision of a steady annal of data quality to support time-series analyses and data "stacking", while controlling incessant improvement of the documentation and access to data as they are acquired. The images were obtained from the United States Geological Survey (USGS) website (https://earthexplorer.usgs.gov). Description of the Landsat imagery is given in Table 1. Although images were non-available for some years, it did not affect the objective since the study was not strictly an annual comparison. Those years with too much cloud cover were not used. Some excellent images were obtained though for these sensors, despite the scan line corrector failure of ETM+. The focal analysis tool was used to correct this. Although some spectral property may have been lost, it had insignificant influence on the quality of the work since mostly the combined bands were for visual interpretation and identification of the built-up areas. Image of 1972 has a size $170 \mathrm{~km} \times 185 \mathrm{~km}$ and on path 207 and row 56 . The rest all have size $170 \mathrm{~km} \times 183 \mathrm{~km}$ and on path 93 and row 56.

Table 1. Spectral descriptions of Landsat imagery and scenes

\begin{tabular}{|c|c|c|c|c|c|c|}
\hline Band name & LS 1-5 MSS & LS 4-5 TM & LS 7 ETM + & LS 8 OLI & \multicolumn{2}{|c|}{ Pixel size (m) } \\
\hline Blue & & $\mathrm{B} 1(0.45-0.52)$ & B1 $(0.45-0.52)$ & $\mathrm{B} 2(0.45-0.51)$ & \multicolumn{2}{|c|}{30} \\
\hline Green & $\mathrm{B} 1, \mathrm{~B} 4(0.5-0.6)$ & B2 $(0.52-0.60)$ & $\mathrm{B} 2(0.52-0.60)$ & B3 $(0.53-0.59)$ & \multicolumn{2}{|c|}{$30(60$ for MSS $)$} \\
\hline Red & B2, B5 (0.6 - 0.7) & B3 $(0.63-0.69)$ & B3 $(0.63-0.69)$ & B1 (0.64 - 0.67) & \multicolumn{2}{|c|}{30 (60 for MSS) } \\
\hline NIR 1 & B3, B6 (0.7 - 0.8) & & & & \multicolumn{2}{|c|}{60} \\
\hline NIR & B4, B7 (0.8 - 1.1) & B4 $(0.76-0.90)$ & B4 $(0.77-0.90)$ & B5 (0.85 - 0.88) & \multicolumn{2}{|c|}{$30(60$ for MSS $)$} \\
\hline SWIR 1 & & B5 (1.55 - 1.75) & B5 (1.55 - 1.75) & B6 (1.57 - 1.65) & \multicolumn{2}{|c|}{30} \\
\hline SWIR 2 & & B7 $(2.08-2.35)$ & B7 $(2.09-2.35)$ & B7 $(2.11-2.29)$ & \multicolumn{2}{|c|}{30} \\
\hline & \multicolumn{4}{|c|}{ Other important information on dataset } & & \\
\hline Number of bands used & 4 & 6 & 6 & 6 & & \\
\hline Radiometric bit & 8 & 8 & 8 & 16 & & \\
\hline Projection & & UTM & UTM & UTM & & \\
\hline \multirow[t]{2}{*}{ Ellipsoid } & WGS 84 & WGS 84 & WGS 84 & WGS 84 & & \\
\hline & Latitude & Longitude & Latitude & Longitude & Path & Row \\
\hline Accra & 5.6037 & -0.1870 & $811610.81 \mathrm{mE}$ & $619856.35 \mathrm{mN}$ & 193 & 56 \\
\hline
\end{tabular}

In all cases the chosen bands (Table 1) were stacked together to provide a composite of all the good usable bands. Corresponding bands were chosen for the respective sensors. One key advantage for using this type of data is the possibility to detect a complete historical profile of urban growth, which is not easily discernible from stacked images with sparse satellite observations (Roy et al., 2014). We also used Google Earth (GE) from (https://earth.google.com) obtained around the same time of the acquisition date of the Landsat imagery for collecting ground truth to serve as training data. Google Earth provided historical records feature samples locations for five classes (i.e. vegetation, open bare land, roads, buildings and water). Bands were combined to visualise where these features are. Using visual interpretation these areas were digitised in GE and saved to shape-file in ArcGIS. For each digitised polygon, a point around the centre was taken and recorded in excel. These served as the ground truth and training 
data for the classification. After the maximum likelihood supervised classification of five classes, a post-classification was done to regrouped into built-up areas (BUP), nonbuilt up areas (NBUP) and water bodies (WB). Here, residential areas, commercial and industrial area are all classified as BUP. Agriculture, Plantation, Recreational Parks, Orchards and Forest are all classified as NBUP. Dams/Reservoirs, Ponds, River, Lakes, Stream are all classified as WB.

\section{Procedure and approach}

We used two band ratio and band combination to extract and classify features from the Landsat imagery. Developed indices serve as an indicator to analyse a particular type of land class during feature extraction and classification processes. In principle, indexing determines a ratio between the strongest (maximum) reflectance band and weakest (minimum) reflectance bands for the target feature. Then the normalised ratio of these two bands gives the highest contrast for the particular land type with minimum background noise. Landsat imagery that showed a significant presence of clouds was avoided. Conversely, Landsat images with less cloud cover outside the area of interest were included, which were subsequently imported into ERDAS Imagine for layer stacking. The focal analysis tool in ERDAS was applied to gap-fill the images that had stripes. The stacked images were later subsetted using shape-files of the study area. All the subset images were then moved to the ENVI environment for classification. The general procedure used is shown in Figure 2.

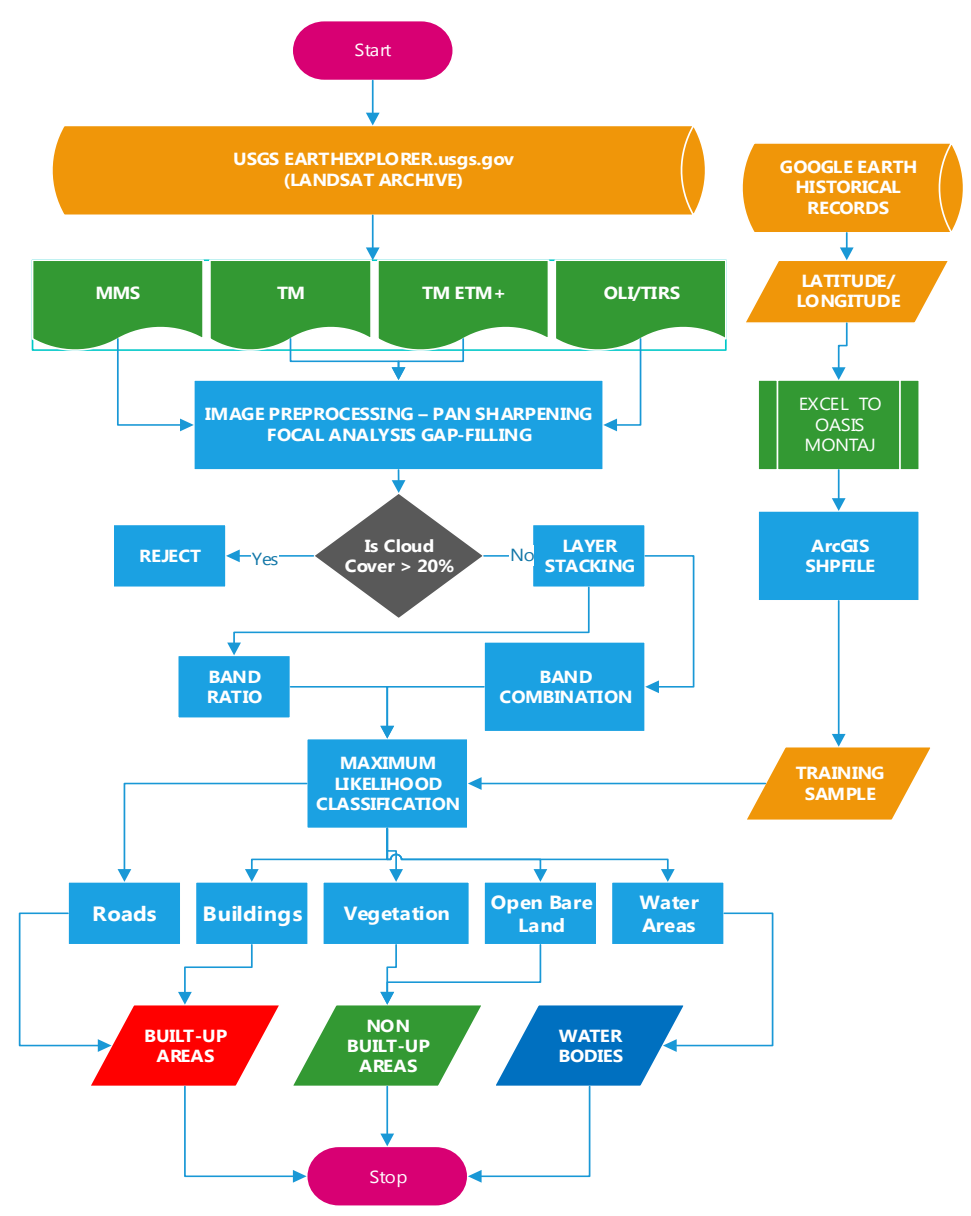

Figure 2. Workflow procedure diagram 


\section{Band combination}

Band combination is an RGB composite that enhances the visual interpretation of the potential information content as shown in Figure 3. RGB composites for Landsat 8 differ from RGB composite obtained from Landsat 7 and Landsat 5 due to the difference in wavelength information for similar band in these images. For instance, a band combination of band 4, band 3 and band 2 create colour infrared (CIR) in Landsat 7 or Landsat 5, whereas the same resulting colour infrared in Landsat 8 is created using band 5 , band 4 and band 3 . Thus, it is imperative to choose a particular band combination dependent on the visual depiction of the preferred feature or phenomena. In this study, we created the following band combination to extract and classify features as described (Fig. 3):

- Bands 7, 4, 2: Urban areas appear in shades of magenta while vegetation appears light green. Light-green spots in the city specify grass-land cover like parks, golf courses, cemeteries.

- Bands 4, 3, 2: Deep red hues designate healthy vegetation while lighter reds show sparsely vegetated areas. Light blue shows densely populated urban areas.

- Bands 4, 5, 3: This blend offers further description of land-water boundaries and highlights subtle details not distinctively apparent in the visible bands. This combination exhibits moisture differences which are useful for soil and vegetation analysis.

- Bands 5, 4, 3: Healthy vegetation is bright green with soils as light purple, and mostly used for agricultural studies. It can also be applied in timber logging management.
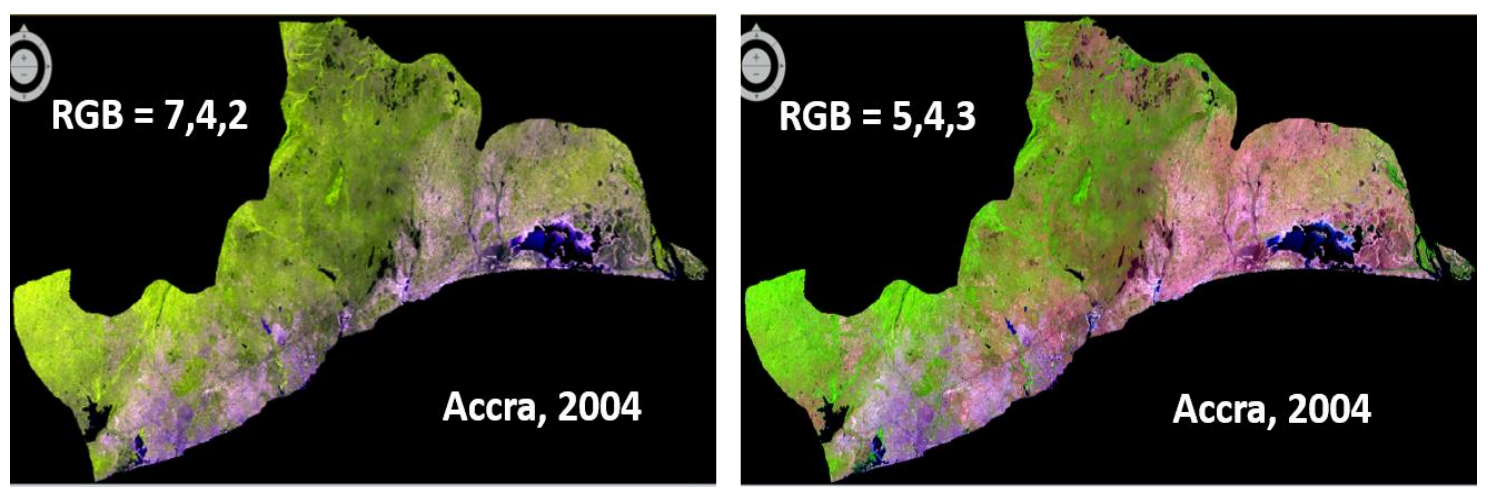

Figure 3. Sample of some band combinations

\section{Band ratio}

The Band Ratio (BR) technique has been applied before for geological interpretation as in (Inzana et al., 2003) and, for detecting mangrove forests as in (Rahman et al., 2013) among others. In these previous studies, band ratio images are evaluated based on their ability to discriminate the target feature (i.e. geologic units and structure; mangrove species). Generally, the illumination effect is removed in the spectral difference for any two-band ratio, in which the difference is the ratio. The illumination defines the magnitude of the DN received by satellite (Muniz et al., 2003). The principle is applied here to detect urban areas. In this study, the stacked images were loaded with 
all the bands, however only the applicable RGB composites are loaded into the viewer for visual interpretation. The whole idea behind this method is to be able to confidently identify the targeted features (vegetation, open bare land, water areas, roads and buildings), on the displayed image to collect appropriate training sample features. Unique information with subtle spectral reflectance is provided by ratios for surface materials often difficult to detect in a standard image (Inzana et al., 2003). The following band ratios were applied to the respective targeted features.

- Roads and buildings - (Band 3/Band 5 and Band 3/Band 4): These sharply defined the urban area and barren land. They enhance barren lands, street patterns, highways in the urban areas and urban built-up or paved areas. Urban and built-up areas appear as brighter tone and forests, water body and croplands appear darker.

- Open bare land - (Band 5/Band 7 and Band 3/Band 5): Land and water are distinctively separated because soils exhibit strong absorption in the band 7 and high reflectance in band 5. Land appears as lighter tone and water appear darker.

- Vegetation - (Band 4/Band 3 and Band 4/Band 5): This discriminate between vegetation, water and croplands which is due to the moisture content. Vegetation reflects higher in near IR region and strong absorption in the red region. The lighter the tone, means more vegetation present.

- Water areas - (Band 4/Band 3, Band 4/Band 5 and Band 5/Band 7): Easily discriminates water bodies from the land. Water absorbs strongly in near IR region and reflects much in band 5. Water body appears darker than vegetation and land which appear lighter.

The mathematical expression of the band ratio function is displayed in Equation 1.

$$
\text { BandRatio }=B R_{i, j, r}=\frac{B N_{i, j, k}}{B N_{i, j, 1}}
$$

where $\mathrm{BR}_{\mathrm{i}, \mathrm{j}, \mathrm{r}}$ is the output ratio value for the pixel, at row $i$, column $j$, and $\mathrm{BN}_{\mathrm{i}, \mathrm{j}, \mathrm{k}}$ and $\mathrm{BN}_{\mathrm{i}, \mathrm{j}, 1}$ is the brightness value at the same location in band $k$ and $l$. Both the numerator and the denomerator factors belong to the same image scene.

\section{Classification method}

We used Maximum Likelihood (ML) algorithm to classify the images (Rawat and Kumar, 2015; Dewan and Yamaguchi, 2009). Maximum Likelihood was preferred over other classification algorithms due to the robust nature of the Gaussian probability distribution in assigning classes (Mather and Tso, 2010). It has successfully been applied in urban and peri-urban areas to monitor land cover changes (Schneider, 2012). We used training sample features that were extracted (digitised) from GE for each of the defined class. Then the band ratio (as described above) was applied for the respective features. We subjected the single band result to a ML supervised classification using the extracted training sample as ground truth. The classification was done for five classes (bare land, vegetation, water, roads, and buildings), which were later aggregated to three classes of built-up areas (roads and buildings), non-built up areas and water bodies, during the post-classification. A kennel smooth size 3 was used to smoothen the result. 
The advantage of this approach is that it can be applied to various Landsat sensors for this purpose, whereas the established indexes are limited to specific sensors because the bands used are not present in all the array of sensors. This approach is also simple as it involves very little mathematics and does not necessarily need an in-depth understanding for implementation.

\section{Change rate and growth rate calculations}

Change and growth rates have been used by (Li et al., 2016; Xu et al., 2011) to examine urban impervious surface distribution and change dynamics where the surface area coverage was determined for various years for Hangzhou and Xiamne cities. Change rate is this paper was calculated using Equations 2 and 3.

$$
\text { ChangeRate }=(C R)=A(x)=\frac{f\left(x_{2}\right)-f\left(x_{1}\right)}{x_{2}-x_{1}}=\frac{y_{2}-y_{1}}{x_{2}-x_{1}}
$$

where $\mathrm{x}_{2}$ is the final year, and $\mathrm{x}_{1}$ is the initial year; the functions are defined as in Equation 3:

$$
\begin{aligned}
& f\left(x_{2}\right)=x_{2}^{2}-\left(2 \times x_{2}\right) \\
& f\left(x_{1}\right)=x_{1}^{2}-\left(2 \times x_{1}\right)
\end{aligned}
$$

Different formulas exist for the calculation of growth rates, however in this study the formula of Equation 4 (Feeney, 2014) was adopted.

$$
\text { GrowthRate }=(G R)=T(x)=\left[\frac{\text { present }}{\text { past }}\right]^{\frac{1}{n}}-1
$$

where present and past represent the figures for the current and past years respectively. $n$ is the interval over which the growth is computed - 10 years for this study (Fig. 7).

To assess the spatial distribution of built-up expansion intensity, an annual urban expansion intensity index (AUEII) by (Liu et al., 2000) was adopted and modified to Built-Up Expansion Intensity Index (BUEII) for use as an indicator of the urbanization rate of the study area. BUEII is expressed as in Equation 5.

$$
B U E I I=\frac{A_{n+i}-A_{i}}{n T A_{n+i}} \times 100 \%
$$

where $T A_{n+i}$ is the total area of the target unit at time $n+i ; A_{n+i}$ and $A_{i}$ the built-up area within the target unit at time $n+i$ and $i$, respectively, and $n$ the interval period (in years).

\section{Accuracy assessment calculation (kappa coefficient)}

The kappa coefficient measures classification and truth values agreement. With a kappa value of 1 there is a perfect agreement, while a value of 0 means no agreement. 
The kappa coefficient mathematically follows Equation 6 but can be simply reduced to Equation 7:

$$
K=\frac{N \sum_{i=1}^{n} m_{i, 1}-\sum_{i=1}^{n}\left(G_{i} G_{i}\right)}{N^{2}-\sum_{i=1}^{n}\left(G_{i} G_{i}\right)}
$$

where $i$ is the class number; $N$ is the total number of classified values compared to truth values; $m_{i, i}$ is the number of values within class $i$ that have also been classified as class $i$ which values are along the diagonal of the confusion matrix; $C_{i}$ is the total number of predicted values within class $I ; G_{i}$ is the total number of truth values within class $i$.

$$
\text { Kappa }=\frac{(N b-g)}{N^{2}-g}
$$

where $N$ is the total number of points; $b$ is the sum of correctly mapped points; $g$ is the sum of the products of classes between the ground truth points used and the predicted points digitised.

\section{Results and analysis}

\section{Accuracy assessment}

We generated the confusion matrix to assess the accuracy of the results. The highest overall accuracy obtained is $87.18 \%$ and a lowest of $81.31 \%$ with a mean accuracy assessment of $84.25 \%$. The Kappa coefficient was used to evaluate the quality of agreement, either positive or negative. The average kappa coefficient for Accra was 0.7618 using Equation 6, which is a simplified rendition for its calculation. The producer accuracy and user accuracy are calculated for each image for each class and are shown in Table 2. It was possible to obtain a producer accuracy of $90.91 \%$ for built-up area in 1987 . The user accuracy for the same year is $84.96 \%$. For built-up areas the producer accuracy ranged between 75.36 and $90.91 \%$, non-built up areas range from 75.00 to $93.27 \%$, and between 81.08 and $92.31 \%$ for water bodies. Figures for water bodies seem high because it was easy to identify them within the chosen band combinations, thus reducing the chances of error. Water can even attain a high accuracy of $100 \%$ (Elhag, 2017).

\section{Analysis on built-up area coverage}

In total, thirteen comparable years were analysed. The entire timeline was divided into five epochs; (i) before 1980, (ii) 1981-1990, (iii) 1991-2000, (iv) 2001-2010 and (v) 2011-2017. These were further grouped into three periods of the early period (first 3 years), mid period (second 3 years) and late period (last 4 years), of each epoch. This approach made the comparison easier and visually comprehensible. A graph of the gains is shown in Figure 4. 
Table 2. Accuracy assessment table

\begin{tabular}{|c|c|c|c|c|c|c|c|c|c|c|}
\hline \multirow{2}{*}{ Year } & \multirow[b]{2}{*}{ PA } & \multirow[b]{2}{*}{ UA } & \multirow[b]{2}{*}{ OVA } & \multirow[b]{2}{*}{$\mathbf{K}$} & \multirow{2}{*}{ Year } & \multirow[b]{2}{*}{$\mathbf{P A}$} & \multirow[b]{2}{*}{$\mathbf{U A}$} & \multirow[b]{2}{*}{ OVA } & \multirow[b]{2}{*}{$\mathbf{K}$} & \multirow{2}{*}{ CLASS } \\
\hline & & & & & & & & & & \\
\hline \multirow{4}{*}{$\stackrel{N}{\hat{\Omega}}$} & 0.8824 & 0.8824 & & & \multirow{4}{*}{ ஓे } & 0.8395 & 0.8831 & & & BUP \\
\hline & 0.7500 & 0.7500 & & & & 0.8667 & 0.8228 & & & NBUP \\
\hline & 0.8889 & 0.8889 & & & & 0.8776 & 0.8776 & & & WB \\
\hline & & & 0.8421 & 0.7548 & & & & 0.8585 & 0.7835 & \\
\hline \multirow{4}{*}{ 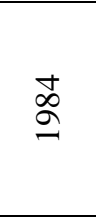 } & 0.7536 & 0.8254 & & & \multirow{4}{*}{ ষ্ণ } & 0.8222 & 0.9136 & & & BUP \\
\hline & 0.8909 & 0.7424 & & & & 0.8831 & 0.8095 & & & NBUP \\
\hline & 0.8108 & 0.8696 & & & & 0.8889 & 0.8571 & & & WB \\
\hline & & & 0.8131 & 0.7195 & & & & 0.8597 & 0.7863 & \\
\hline \multirow{4}{*}{$\stackrel{\infty}{\infty}$} & 0.9091 & 0.8929 & & & \multirow{4}{*}{ ঠ্ণ } & 0.8163 & 0.8791 & & & BUP \\
\hline & 0.7778 & 0.7955 & & & & 0.8667 & 0.9176 & & & NBUP \\
\hline & 0.8485 & 0.8485 & & & & 0.8730 & 0.7333 & & & WB \\
\hline & & & 0.8496 & 0.7695 & & & & 0.8486 & 0.7713 & \\
\hline \multirow{4}{*}{$\begin{array}{l}\curvearrowright \\
\stackrel{0}{-}\end{array}$} & 0.8243 & 0.9385 & & & \multirow{4}{*}{ 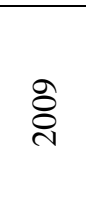 } & 0.7895 & 0.8911 & & & BUP \\
\hline & 0.8621 & 0.7937 & & & & 0.8889 & 0.7921 & & & NBUP \\
\hline & 0.8929 & 0.7813 & & & & 0.8657 & 0.8406 & & & WB \\
\hline & & & 0.8500 & 0.7635 & & & & 0.8413 & 0.7583 & \\
\hline \multirow{4}{*}{ ๙ૂ } & 0.7927 & 0.8904 & & & \multirow{4}{*}{$\underset{\bar{\sigma}}{\bar{\nu}}$} & 0.8148 & 0.9483 & & & BUP \\
\hline & 0.8551 & 0.7867 & & & & 0.9327 & 0.8220 & & & NBUP \\
\hline & 0.8824 & 0.8333 & & & & 0.8904 & 0.8333 & & & WB \\
\hline & & & 0.8366 & 0.7521 & & & & 0.8718 & 0.8041 & \\
\hline \multirow{8}{*}{$\stackrel{\curvearrowleft}{2}$} & 0.8182 & 0.9231 & & & \multirow{4}{*}{$\stackrel{ \pm}{\stackrel{্}{\triangle}}$} & 0.8156 & 0.8984 & & & BUP \\
\hline & 0.8955 & 0.7792 & & & & 0.8673 & 0.7870 & & & NBUP \\
\hline & 0.8333 & 0.8333 & & & & 0.8919 & 0.8571 & & & WB \\
\hline & & & 0.8469 & 0.7673 & & & & 0.8498 & 0.7688 & \\
\hline & & & & & \multirow{4}{*}{ 홍 } & 0.7947 & 0.9160 & & & BUP \\
\hline & & & & & & 0.9135 & 0.7787 & & & NBUP \\
\hline & & & & & & 0.8676 & 0.8429 & & & WB \\
\hline & & & & & & & & 0.8483 & 0.7641 & \\
\hline
\end{tabular}

BUP $=$ Built Up Areas; NBUP $=$ Non-Built Up areas; $\mathrm{WB}=$ Water Bodies; PA = Producer Accuracy; $\mathrm{UA}=$ User Accuracy; OVA = Overall Accuracy; $\mathrm{K}=$ Kappa

Non-built up areas generally lost to built-up areas steadily with some anomalies in 2011 and 2008. These anomalies, we think, may be due to the migration from ruralurban into the urban centres which may have contributed to a drastic increase in built-up areas. Constant urban development picked up around these times, and it is fully represented in the graph (Fig. 4). Information presented in Figure 5 compliments that of Figure 4. Gaps within the graph indicate years with no data (images). Either images were avoided entirely due to cloud cover or it was missing (sensor failure). The complete mapped area coverages are shown in Table 3. It shows the corresponding area coverage of the land covers for respective years. 


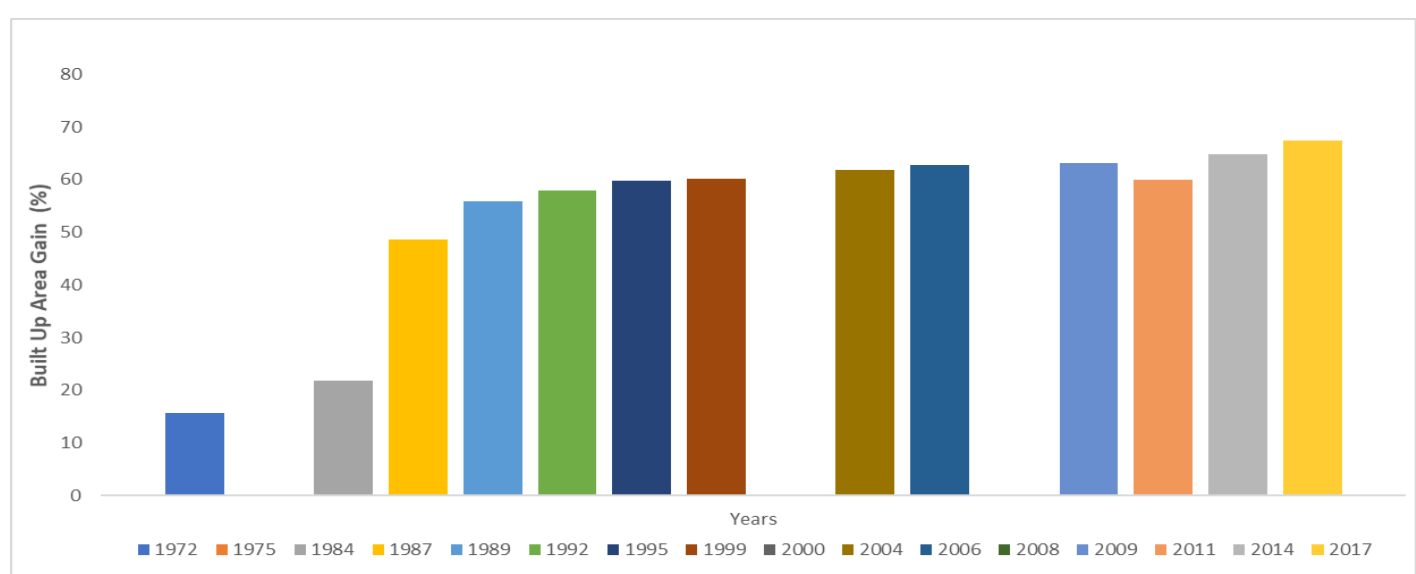

Figure 4. Graph of built up areas coverage in percentages (\%)

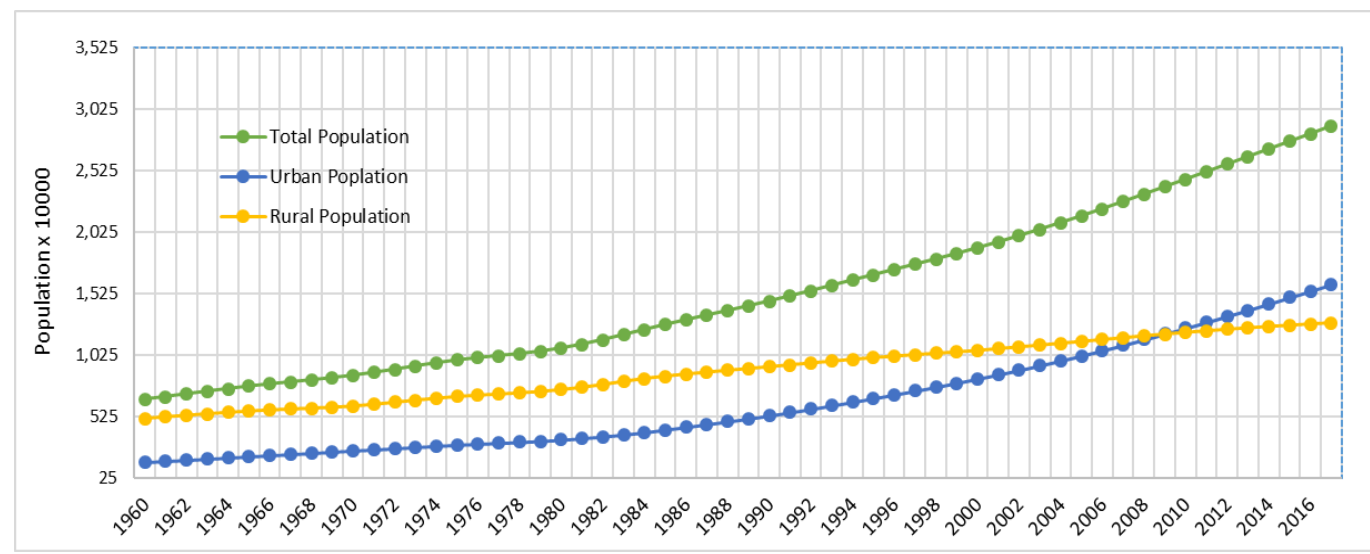

Figure 5. Population growth in urban and rural areas in Ghana

Table 3. Results for area coverage of classification in percentages (\%)

\begin{tabular}{c|c|c|c|c|c|c|c}
\hline \multicolumn{7}{c|}{ Treater Accra Region } & \multirow{2}{*}{$\begin{array}{c}\text { Annual percentage } \\
\text { BUP increase based } \\
\text { on Equation 5 }\end{array}$} \\
\hline Year & BUP\% & $\mathbf{k m}^{2}$ & NBUP\% & $\mathbf{k m}^{\mathbf{2}}$ & $\mathbf{W B \%}$ & $\mathbf{k m}^{\mathbf{2}}$ & $0.52 \%$ \\
\hline 1972 & 15.65 & 507.84 & 68.49 & 2222.50 & 15.86 & 514.66 & \\
\hline 1984 & 21.87 & 709.68 & 63.85 & 2071.93 & 14.28 & 463.39 & \\
1987 & 48.69 & 1579.99 & 37.33 & 1211.36 & 13.98 & 453.65 & $5.68 \%$ \\
1989 & 55.94 & 1815.25 & 30.23 & 980.96 & 13.83 & 448.78 & \\
\hline 1992 & 57.82 & 1876.26 & 28.38 & 920.93 & 13.80 & 447.81 & \\
1995 & 59.84 & 1941.81 & 26.40 & 856.68 & 13.76 & 446.51 & $0.23 \%$ \\
1999 & 60.12 & 1950.89 & 26.25 & 851.81 & 13.63 & 442.29 & \\
\hline 2004 & 61.78 & 2004.76 & 24.66 & 800.22 & 13.56 & 440.02 & \\
2006 & 62.65 & 2032.99 & 23.94 & 776.85 & 13.41 & 435.15 & $0.27 \%$ \\
2009 & 63.12 & 2048.24 & 23.53 & 763.55 & 13.35 & 433.21 & \\
\hline 2011 & 59.89 & 1943.43 & 26.85 & 871.28 & 13.26 & 430.29 & \\
2014 & 64.81 & 2103.08 & 22.31 & 723.96 & 12.88 & 417.96 & $1.24 \%$ \\
2017 & 67.32 & 2184.53 & 19.92 & 646.40 & 12.76 & 414.06 & \\
\hline
\end{tabular}

BUP $=$ Built Up Areas; NBUP $=$ Non-Built Up areas; WB $=$ Water Bodies 


\section{Analysis on built-up change rate}

This rate gives an indication of when much built up occurred which can be a measure of the economic status of the region. With an argument, it is assumed that the citizens and not the government do the built-up activities. The change rate is shown in Figure 6. It was calculated using Equations 2 and 3 (Phiri and Nyirenda, 2015). In the second epoch (1991-2000), Accra added 3.83\% more to its built-up environment but there was a slight increase of $2.12 \%$ during the third epoch (2001-2010). Notwithstanding this small increase it did an increase of 11.04\% over the period (2011-2017). By 1980, the built-up areas had increased from $15.65 \%$ in 1972 to $21.87 \%$ representing a land surface area of $507.84 \mathrm{~km}^{2}$ and $709.68 \mathrm{~km}^{2}$, respectively, an increase of only $0.19 \%$. However, by 1989 , over $15-17$ years, the built-up areas occupied $55.94 \%$ of surface area. The highest change occurred between 2001 and 2005 and the lowest occurred between 1996 and 2000 against the previous years, over the last 35 years. The last column of Table 3 gives annual percentage increase in built-up areas depicting the annual change in size.

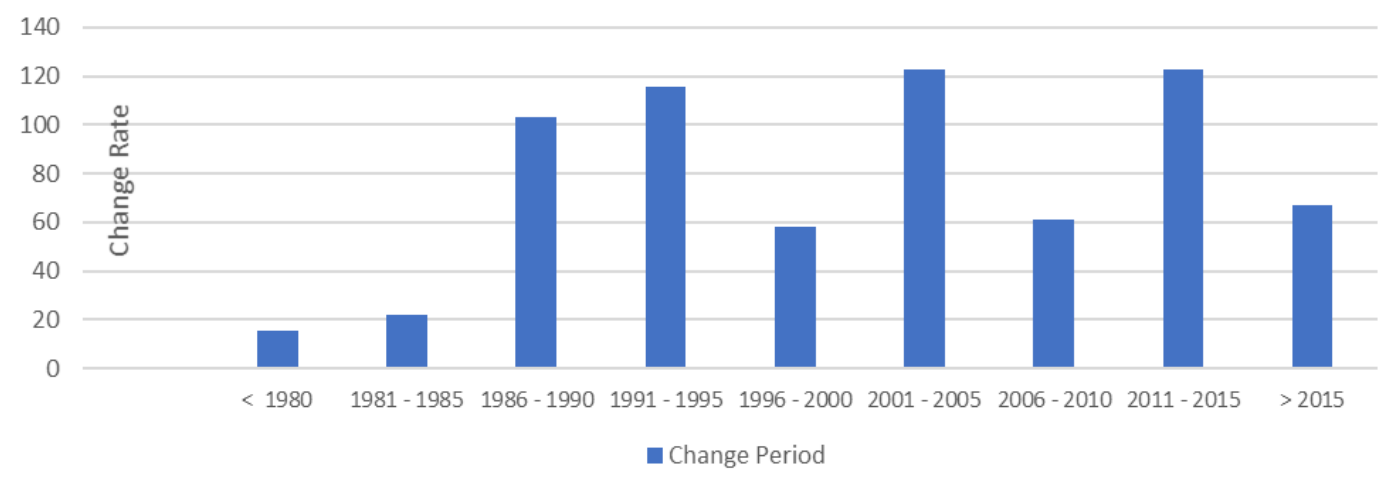

Figure 6. Graph of annual built-up change rate

\section{Analysis on built-up growth rate}

The GR over the period 1984-1994, 1995-2005 and 2006-2016 were 10.19\%, 0.32\%, and $0.34 \%$ respectively. Over the entire period of 1984-2017, Accra had a built-up growth rate of $11.9 \%$. This figure, a graph of which is in Figure 7, does not necessarily mean lack of development (urbanisation) but rather it tells the spatial coverage of development or urbanisation within the region. The high growth rate of Accra in the first decade from 1984 is attributed to stable political environment after various coup d'états from 1966 until 1979. Although it was a military regime for almost the entire period, the country had a stable environment for growth.

There was coup d'état around this time, the economy of the country was very bad and this resulted in a lot of people leaving the country for greener pastures. Built-up areas within the capital were just very low as the economic status of the citizenry was not encouraging. The 1972 urban built-up scenario is depicted in Figure 8.

By 1984, the country had a stable government and economic activities had picked up. The country was implementing the Structural Adjustment Programme (SAP) as the 
building foundation of the economy which was destroyed over the 15-year coup d'état period. Physical infrastructure was pursued vigorously by government which resulted in a constant growth by the year 1992 when the country returned to constitutional governance. Figure 9 shows the change between 1984 and 1992.

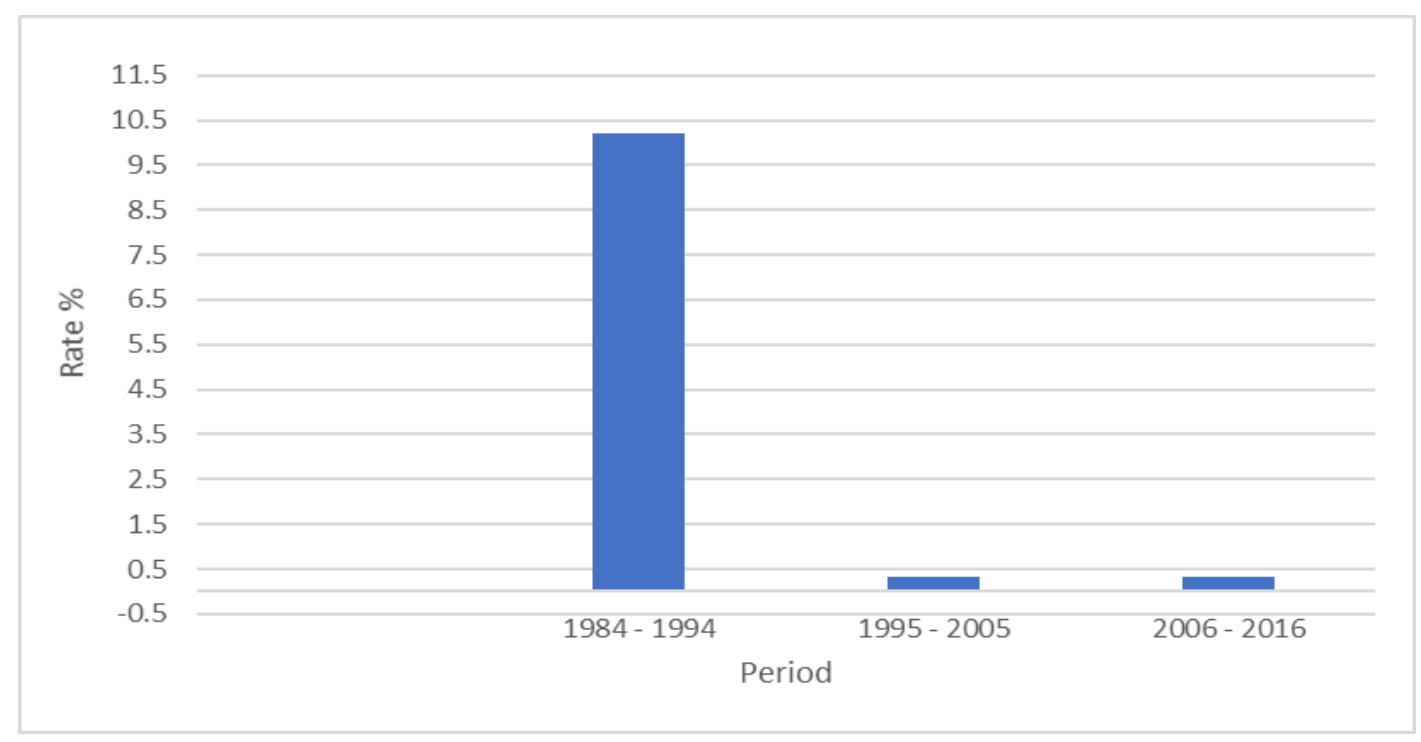

Figure 7. Decade analysis of built up growth rate

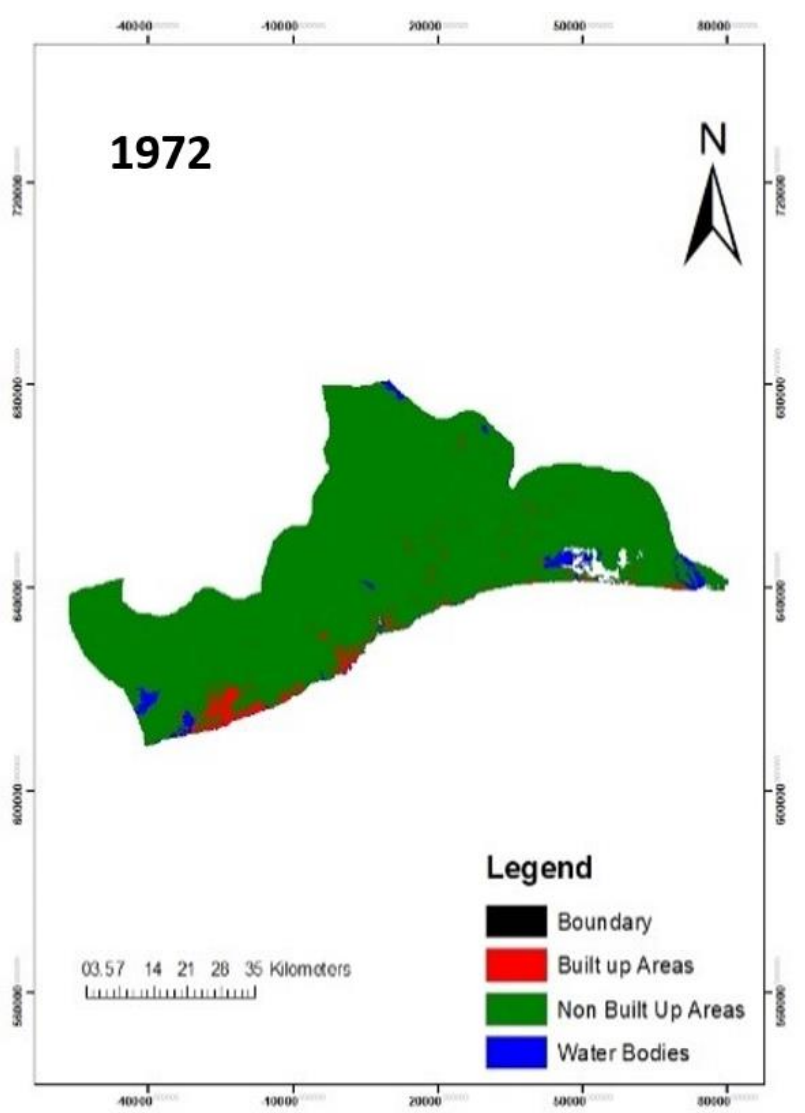

Figure 8. Map land cover-baseline comparison 1972 

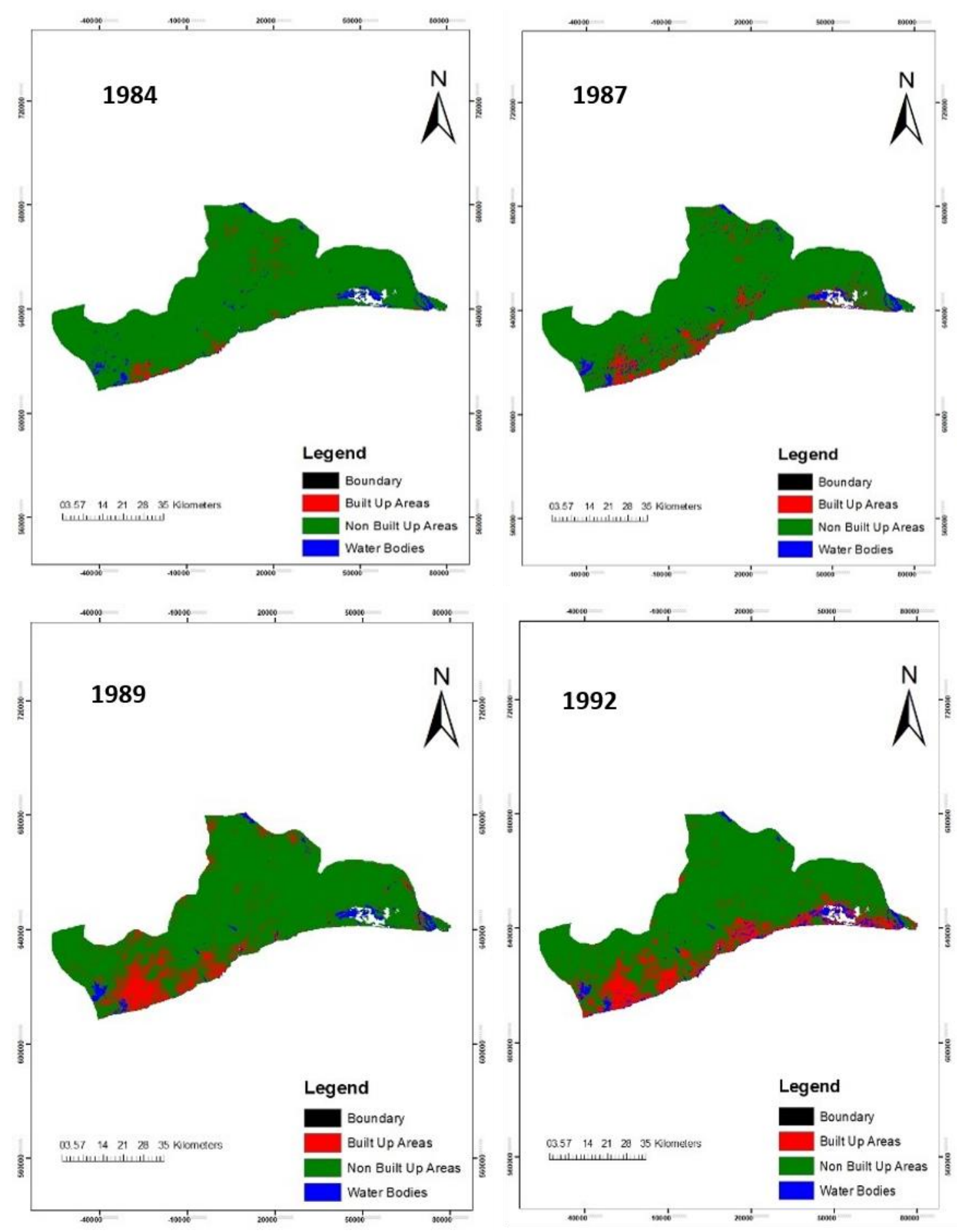

Figure 9. Map of land cover classification - selected years

Between 1993 and 1999, there was less development because greater portion of resources was channelled in expanding the country through electrification projects and building of feeder roads. Much of the built up activities was experienced mostly outside the economic capital. After the debt cancellation in 2001, the government had economic space to accelerate infrastructure once more and this increased the built up areas. The gradual increase is adequately shown in Figure 10. 


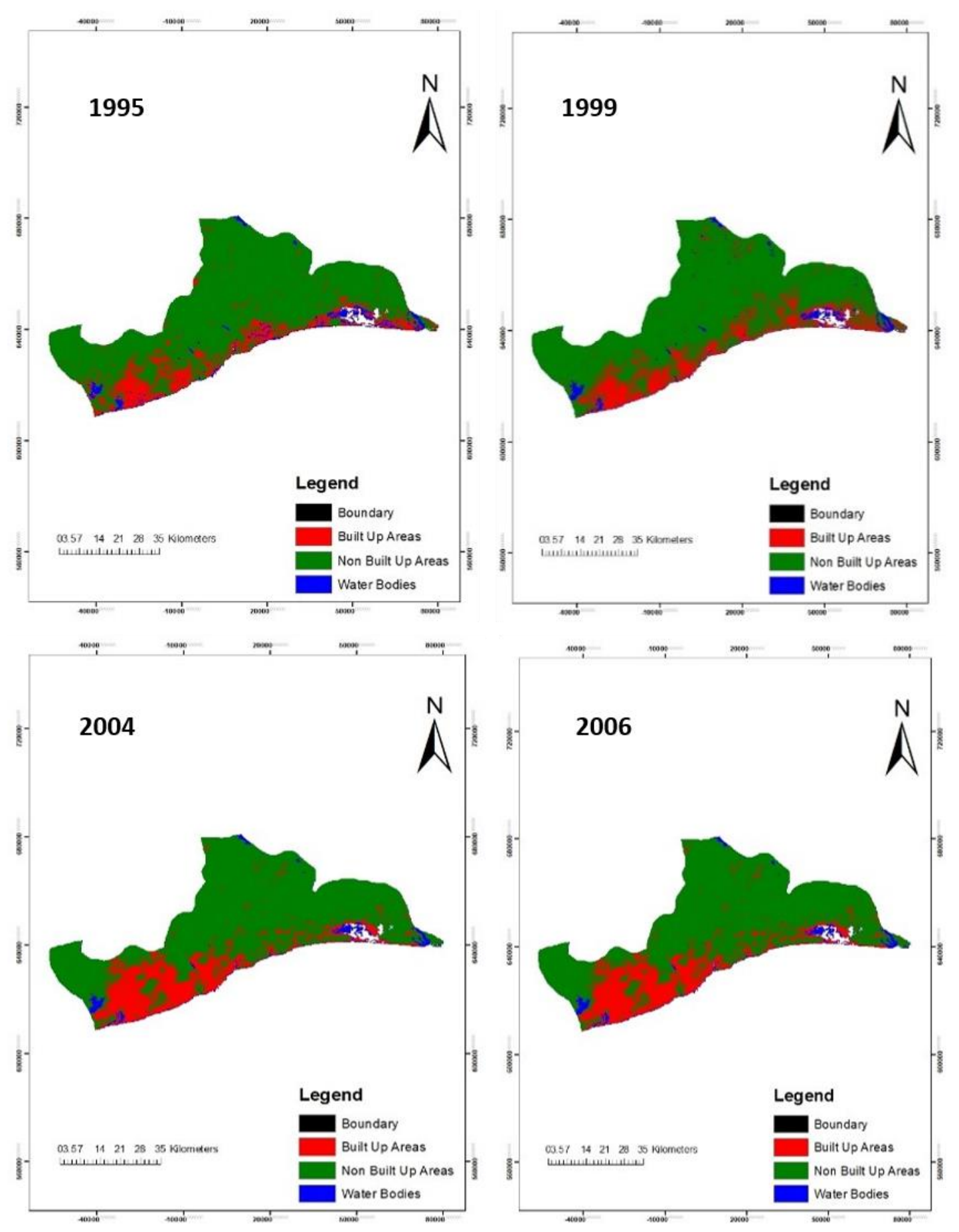

Figure 10. Map of land cover classification - selected years

There was a setback in 2007 and 2009 following flooding disaster which resulted in a massive demolishing of structures put up on water ways (dried up streams). The rapid increase in population and massive migration to the economic capital between 2010 and 2014 resulted in rapid housing projects to accommodate the influx. These have their own associated problems as demolishing of houses continues whenever there is flooding. This has seemingly slowed the rapid built up of infrastructure expansion. Figure 11 shows the apparent scenarios explained above. 


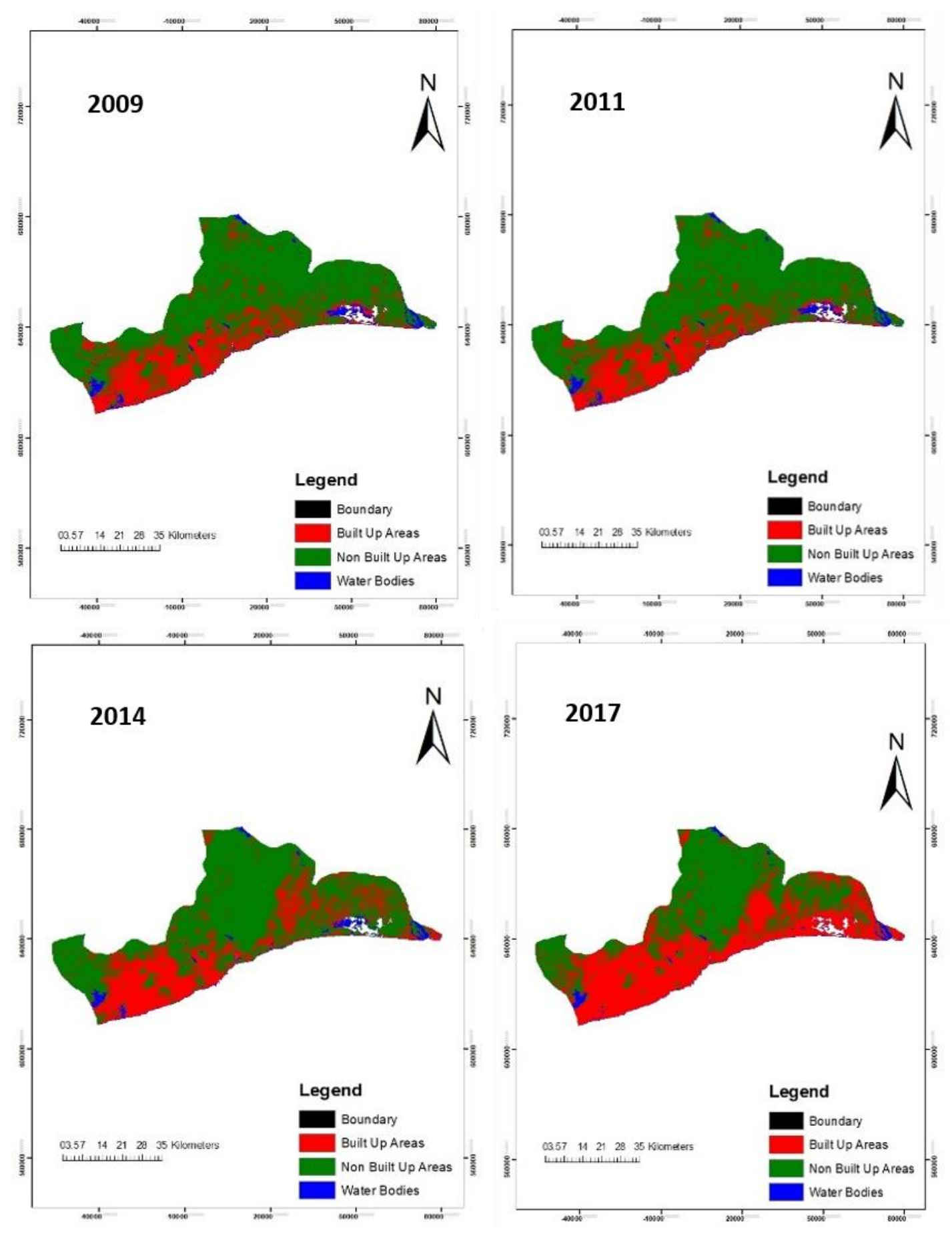

Figure 11. Map of land cover classification - selected years

\section{Analysis on non built-up and water bodies performance}

Results of the Area coverage percentage indicate a sharp loss of non-built up areas between 1981 and 1987. The 26.52\% loss between 1984 and 1987 matches with the $26.82 \%$ gain in built up for the same time period. Water bodies lost $3.1 \%$ within 37 years translating into an annual loss of $0.08 \%$. The highest loss value for water body 
areas is only $1.58 \%$ between 1972 and 1984 . In between comparable years, water body areas did not decline by even $1 \%$.

\section{Discussion}

\section{Band ratios and band combination}

This is a very important image processing technique. The DN value of each pixel of one band is divided by the corresponding pixel value of another band. This yielded new number sets from zero (0/1) to $255(255 / 1)$ which highlight more the specific target feature while suppressing the others. When necessary a rescaling can be done to provide a gray tone image resulting in a truer image because effect of shadows (or topographic) are dealt with (Zhouyu et al., 2006). This is an important advantage because eliminating shadows is still a challenge in a mixed urban environment during classification. Rescaling was not done in this study. Two distinct advantages result from band ratios; the differences in spectral reflectance curves of surface types are highlighted, and then illumination and radiance differ. Band rationing has the effect of removing shadows.

Another important property of two band ratios is that some features can be recognized by simply observing a single ratio. Many band ratios exist but involve the use of more than two bands. A few two band ratios exist but are mostly related to lithological discrimination and mapping and applications in hyperspectral image analysis (Simon et al., 2016; Mohammad et al., 2001).

The spectral reflectance curves, of ground targets provide great insight for information extraction. Usually ratio results of 1 or more is expected since pixels of ratios less than unity is characterized by dark signatures. Hence, ratio bands calculations were chosen to give values more than unity or close to unity. Between any two bands, which will be the numerator and which will be the denominator is carefully adjusted.

\section{Maximum likelihood classification}

As a parametric statistical classifier, the analyst training samples are numerically presented to the classifier algorithm by assuming that the distribution of the training sample is normally distributed. All unclassified pixels are assigned classes within the probability density function (Lillesand et al., 2015). The greatest advantage with ML is the quality of training samples. Training samples were collected in a homogeneous cover types as much as possible, since Google Earth provide a high resolution visually for good collection. The classifier develops signatures by taking advantage of the spectra of training set pixels which includes the contributions of all the materials in the training set. It is robust for most topographic and climatic variations which were tested in this study due to the stretch of time period over which topography had been affected due to urbanization. During evaluation in the accuracy assessment, it was manifest that while ML provide higher rates of correct recognition, it also yielded some false alarms. Maximum Likelihood classifier over the years has supported by many remote sensing and geographic information system based software such as ERDAS, with a straight forward in implementation.

\section{Google Earth data}

Digitizing training samples for ground truth from this platform gives geometricallycorrected high-resolution image. This serves as a great free source of validating data 
because Google Earth can go back in time to give a real time training data. Google Earth provide high-resolution image that is coupled with other datasets for effective detection and classification (Xu et al., 2016). The class of water bodies like rivers and lakes is featured by their fairly better pixel uniformity and good spectral discrimination. The classification results using a combination of GE imagery and object-based classification techniques can attain an overall accuracy above 70.00\% (Hu et al., 2013), which seem to be the situation in this paper.

\section{Statistical analysis on delineated features}

As of 2017 the total urban built-up land occupied in Accra was $2184.53 \mathrm{~km}^{2}$. Total coverage of built up in Accra before 1972 was $507.84 \mathrm{~km}^{2}$ but gained as much as $597.73 \mathrm{~km}^{2}(34.07 \%)$ between 1981 and 1990 to reach $1815.25 \mathrm{~km}^{2}$. During the second epoch of 1991-2000, the total coverage moved from $1876.26-1950.89 \mathrm{~km}^{2}$. It increased only from 2004.76 to $2048.24 \mathrm{~km}^{2}$ within the third epoch of 2001-2010. From 20112017 it added up to $241.10 \mathrm{~km}^{2}$ in coverage. These figures are different from the results obtained by (Osei et al., 2013). According to their findings, urban areas covered $534.2279 \mathrm{~km}^{2}$ in 2014 but our results indicate $2103.08 \mathrm{~km}^{2}$ for the same year. We are inclined to say, their analysis might be off since the total land size of Accra as indicated by them is $3693.69 \mathrm{~km}^{2}$ in 1985 and $3694.70 \mathrm{~km}^{2}$ in 2014 . This is problematic since Greater Accra region was not demarcated again in 2014. The total size since 1960 has remained $3245 \mathrm{~km}^{2}$ and not what was obtained by them. Again areas covered by water have declined since 1985 due to buildings springing up on waterways which eventually dries the streams. It lost from $15.86 \%$ in 1972 to $2.88 \%$ by 2014 . What is left now are the big rivers and big drains. However, their results showed very little change, $11.80 \%$ in 1985 to $11 \%$ in 2014. Over the period of 1984-1994, Accra increased its built up areas $7.2 \%$. Over the 37 -year study period, non-built up areas lost almost $49 \%$ to builtup areas because it gained by almost the same margin by 2017. Water bodies remained fairly stable with only $3.1 \%$ decrease over 37 years which means it lost $0.084 \%$ annually.

\section{Conclusions}

Remote sensing has the exclusive capability to support the extraction of urban features to detect urban growth with associated by-problems as, rise in surface temperatures, high traffic volume or population assessment. Change is very regular with all cities. These changes have both temporal and spatial characteristics which transformations can be temporally measured. Multi-year remote sensing information offers an essential source for monitoring and evaluating these endless changes with sufficient information for spatial urban growth investigation at regional level and at varied spatial and temporal scales. Understanding dynamic interaction between diverse aspects of urban expansion as expansion of built-up area and construction activities is very important as it is a very essential indicator of economic growth of a country. Again, the extraction of urban land-cover and land-use studies help to answer questions associated with these interrelations and its endless changes.

Band ratios have been used for many years in the field of remote sensing to classify terrain cover types. In this paper, we have shown the potential of spectral band ratio features for accurate pixel classification. Two band ratio combinations created in this study exhibit a better discrimination of urban features and patterns of urban growth. It 
looked at the growth rate, growth change and the spatial area coverage of the economic capital of Ghana. This paper utilised the entire archive of Landsat data and does a 10year varied-year analysis unlike other depiction of only two years, which is inadequate for in-depth analysis. Every algorithm has its own strengths and flaws. To effectively detect built-up areas based on a chosen algorithm, the nature of the input data is important. Depending on the output of this study, we can primarily say that, the quality of the training data required in supervised classification added to the success of the classification stage.

There were some inconsistencies in the built-up rate but this may be attributed to an uncoordinated land tenure system in the city which resulted in settlements springing up at hitherto odd inhabited places. This occurrence add-up positively because they all contribute to the built-up areas. Also, it can negatively impact because during digitising such sparse small areas might not be classified at all, or could be wrongly classified. The study provided here gives information that can be used by decision makers to make informed decisions on spatial planning, economic policy drafting and a real realisation of the translated impact of government economic policies as there is a direct relation between population growth, urbanisation, infrastructure deficits and GDP. Outputs present readers a guide on spectral diversity, band combination and accuracy assessment for urban areas detection.

Finally, the freely obtainable and accessible Google Earth data coupled with the high spatial resolution can serve as a reliable and effective source of data in urban land-use and land-cover mapping and change detection analysis. Another benefit of Google Earth is that it offers images at different time period which is very useful for urban engineers for land-use change detection studies. Although GE has more advantages, few studies have been done on the use of this data source for land-use mapping. Except for its spectral characteristics, it can make full use of the spatial features of objects, which can, to some degrees, strengthen the advantages of GE based data for its high spatial resolution and compensate its limitation of poor spectral information. This paper contributes to the search for simple use of basic classification techniques to classify urban areas over large geographical areas. It was able to adequately classify the targeted features.

Acknowledgements. This research was funded by the National Key R \& D plan on Strategic International Scientific and Technological Innovation Cooperation special project (2016YFE0202300), Fundamental Research Funds for the Central Universities (2042016kf0179 and 2042016kf1019), the Wuhan Chen Guang project (2016070204010114), the Guangzhou Science and Technology project (201604020070), the Special Task of Technical Innovation in Hubei Province project (2016AAA018), and the Natural Science Foundation of China (61671332, 41771452 and 41771454).

\section{REFERENCES}

[1] Angel, S., Parent, J., Civco, D. L., Blei, A., Potere, D. (2011): The dimensions of global urban expansion: Estimates and projections for all countries, 2000-2050. - Progress in Planning 75(2): 53-107.

[2] Chester, L., Arnold, J., Gibbons, C. J. (1996): Impervious surface coverage: the emergence of a key environmental indicator. - Journal of the American Planning Association 62(2): 243-258.

[3] Cobbinah, P. B., Niminga-Beka, R. (2017): Urbanisation in Ghana: residential land use under siege in Kumasi central. - Cities 60: 388-401. 
[4] Defries, R. S., Rudel, T., Uriarte, M., Hansen, M. (2010): Deforestation driven by urban population growth and agricultural trade in the twenty-first century. - Nature Geoscience 3(3): 178-181.

[5] Dewan, A. M., Yamaguchi, Y. (2009): Using remote sensing and GIS to detect and monitor land use and land cover change in Dhaka Metropolitan of Bangladesh during 1960-2005. - Environmental Monitoring and Assessment 150(1-4): 237-249.

[6] Elhag, M. (2017): Consideration of Landsat-8 spectral band combination in typical Mediterranean forest classification in Halkidiki, Greece. - Open Geosciences 9(1): 468479.

[7] Estoque, R. C., Murayama, Y. (2015): Intensity and spatial pattern of urban land changes in the megacities of Southeast Asia. - Land Use Policy 48: 213-222.

[8] Feeney, G. (2014): Demography 101: population growth rates. - The DemographyStatistics-Information Technology Letter \#9.

[9] Ghana Statistical Service (2014): 2010 Population \& Housing Census. - Accra Metropolitan District Analytical Report.

[10] Ghosh, S., Singh, P., Kumari, M. (2017): Assessment of urban sprawl and land use change dynamics, using remote sensing technique. A study of Kolkata and surrounding periphery, WB, India. - NGCT 2017 : 3rd International Conference on Next Generation Computing Technologies - Springer, Scopus, SCIE, Web of Science, DBLP. 30-31 October, Dehradun, India.

[11] Giles-Corti, B., Kerr, J., Pratt, M. (2017): Contributing to helping to achieve the UN sustainable development goals: truly shifting from niche to norm. - Preventive Medicine 103(September): S1-S2.

[12] Giridharan, R., Ganesan, S., Lau, S. S. Y. (2004): Daytime urban heat island effect in high-rise and high-density residential developments in Hong Kong. - Energy and Buildings 36(6): 525-534.

[13] Guo, W., Lu, D., Wu, Y., Zhang, J. (2015): Mapping impervious surface distribution with integration of SNNP VIIRS-DNB and MODIS NDVI Data. - Remote Sensing 7(9): 12459-12477.

[14] Hettiarachchi, M., Morrison, T. H., Wickramsinghe, D., Mapa, R., De Alwis, A., McAlpine, C. A. (2014): The eco-social transformation of urban wetlands: A case study of Colombo, Sri Lanka. - Landscape and Urban Planning 132: 55-68.

[15] Hu, Q., Wu, W., Xia, T., Yu, Q., Yang, P., Li, Z., Song, Q. (2013): Exploring the use of Google Earth imagery and object-based methods in land use/cover mapping. - Remote Sensing 5(11): 6026-6042.

[16] Inzana, J., Kusky, T., Higgs, G., Tucker, R. (2003): Supervised classifications of Landsat TM band ratio images and Landsat TM band ratio image with radar for geological interpretations of central Madagascar. - Journal of African Earth Sciences 37(1-2): 5972.

[17] Jokar Arsanjani, J., Helbich, M., de Noronha Vaz, E. (2013): Spatiotemporal simulation of urban growth patterns using agent-based modeling: the case of Tehran. - Cities 32: $33-42$.

[18] Kolokotroni, M., Shittu, E., Santos, T., Ramowski, L., Mollard, A., Rowe, K., Wilson, E., Filho, J. P. de B., Novieto, D. (2018): Cool roofs: high tech low cost solution for energy efficiency and thermal comfort in low rise low income houses in high solar radiation countries. - Energy and Buildings 176: 58-70.

[19] Kuang, W., Chi, W., Lu, D., Dou, Y. (2014): A comparative analysis of megacity expansions in China and the U.S.: patterns, rates and driving forces. - Landscape and Urban Planning 132: 121-135.

[20] Li, L., Lu, D., Kuang, W. (2016): Examining urban impervious surface distribution and its dynamic change in Hangzhou metropolis. - Remote Sensing 8(265): 19-24. 
[21] Li, X., Yeh, A. G. O. (2000): Modelling sustainable urban development by the integration of constrained cellular automata and GIS. - International Journal of Geographical Information Science 14(2): 131-152.

[22] Li, X., Liu, X., Gong, P. (2015): Integrating ensemble-urban cellular automata model with an uncertainty map to improve the performance of a single model. - International Journal of Geographical Information Science 29(5): 762-785.

[23] Li, X., Zhou, Y., Zhu, Z., Liang, L., Yu, B., Cao, W. (2018): Mapping annual urban dynamics (1985-2015) using time series of Landsat data. - Remote Sensing of Environment 216: 674-683.

[24] Liu, S., Chuan-jun, W., Hong-quan, S. (2000): A GIS based model of urban land use growth in Beijing. - Acta Geographica Sinica 55(4): 407-416.

[25] Lu, J., Chen, J. H., Tang, Y., Feng, Y., Wang, J. S. (2007): High-rise buildings versus outdoor thermal environment in Chongqing. - Sensors 7(10): 2183-2200.

[26] Mather, P., Tso, B. (2010): Classification Methods for Remotely Sensed Data. $2^{\text {nd }}$ Ed. CRC, Boca Raton.

[27] Mohammad, M. R., El-Sobky, H., Sedeik, K., Raey, M. El (2001): Application of Band Ratios Identified by HHRR for Recognition of Surface Units using TM Data in SIWA Depression, Western Desert, Egypt. - 22nd Asian Conference on Remote Sensing, 5-9 November 2001, Singapore. Centre for Remote Sensing Imaging, Sensing and Processing (CRISP).

[28] Mohammady, S., Delavar, M. R., Pijanowski, B. C. (2013): Urban growth modelling with artificial neural network and logistic regression. Case study: Sanandaj City, Iran. Romanian Review of Regional Studies IX (2): 47-60.

[29] Mu, D., Resources, N., Lafayette, W. (2006): Modelling urbanization patterns in two diverse regions of the world. - Journal of Land Use Science 1(2-4): 83-108.

[30] Muniz, R., Garcia, S., Gonzalez, F., Corrales, J. A. (2003): Use of band rationing for color texture classification. - IbPRIA 606-615.

[31] Osei, F. E., Olutayo Balogun, B., Afrifa, G. (2013): Identifying and quantifying urban sprawl in the Greater Accra Region of Ghana from 1985 to 2014. - International Journal of Science and Research 4(1): 2793-2798.

[32] Phiri, L., Nyirenda, E. (2015): Urban growth analysis for Lusaka City using remote sensing and GIS. - DII-2015 Conference (Development and Investment in Infrastructure Conference). 16-18 September, Livingstone, Zambia.

[33] Potts, D. (2012): Challenging the myths of urban dynamics in Sub-Saharan Africa: the evidence from Nigeria. - World Development 40(7): 1382-1393.

[34] Rahman, M., Ullah, R., Lan, M., Sri Sumantyo, J. T., Kuze, H., Tateishi, R. (2013): Comparison of Landsat image classification methods for detecting mangrove forests in Sundarbans. - International Journal of Remote Sensing 34(4): 1041-1056.

[35] Rawat, J. S., Kumar, M. (2015): Monitoring land use/cover change using remote sensing and GIS techniques: a case study of Hawalbagh block, district Almora, Uttarakhand, India. - Egyptian Journal of Remote Sensing and Space Science 18(1): 77-84.

[36] Roy, D. P., Wulder, M. A., Loveland, T. R., C. E., W., Allen, R., Gerson, M. C., Helder, D., Irons, J. R., Johnson, D. M., Kennedy, R., Scambos, T. A., Schaaf, C. B., Schott, J. R., Sheng, Y., Vermote, E. F., Belward, A. S., Bindschadler, R., Cohen, W. B., Gao, F., Hipple, J. D., Hostert, P., Huntington, J., Justice, C. O., Kilic, A., Kovalskyy, V., Lee, Z. P., Lymburner, L., Masek, J. G., McCorkel, J., Shuai, Y., Trezza, R., Vogelmann, J., Wynne, R. H., Zhu, Z. (2014): Landsat-8: science and product vision for terrestrial global change research. - Remote Sensing of Environment 145: 154-172.

[37] Satterthwaite, D. (2010): The role of cities in sustainable development. - Sustainable Development Insights 4: 1-8.

[38] Schneider, A. (2012): Monitoring land cover change in urban and peri-urban areas using dense time stacks of Landsat satellite data and a data mining approach. - Remote Sensing of Environment 124: 689-704. 
[39] Senanayake, I. P., Welivitiya, W. D. D. P., Nadeeka, P. M. (2013): Urban green spaces analysis for development planning in Colombo, Sri Lanka, utilizing THEOS satellite imagery - a remote sensing and GIS approach. - Urban Forestry and Urban Greening 12(3): 307-314.

[40] Seto, K. C., Kaufmann, R. K., Woodcock, C. E. (2000): Landsat reveals China's farmland reserves, but they're vanishing fast. - Nature 406(6792): 121.

[41] Sharma, R. C., Tateishi, R., Hara, K., Gharechelou, S., Iizuka, K. (2016): Global mapping of urban built-up areas of year 2014 by combining MODIS multispectral data with VIIRS nighttime light data. - International Journal of Digital Earth 9(10): 1004-1020.

[42] Simon, N., Ali, C. A., Mohamed, K. R., Sharir, K. (2016): Best band ratio combinations for the lithological discrimination of the Dayang. - Sains Malayasiana 45(5): 659-667.

[43] Sobrino, J. A., Oltra-Carrió, R., Sòria, G., Bianchi, R., Paganini, M. (2012): Impact of spatial resolution and satellite overpass time on evaluation of the surface urban heat island effects. - Remote Sensing of Environment 117: 50-56.

[44] Songsore, J. (2010): The Urban Transition in Ghana: Urbanization, National Development and Poverty Reduction. - Accra, Ghana.

[45] The World Bank Group (2015): Rising through Cities in Ghana: Ghana Urbanization Review Overview Report. - World Bank, Washington, DC.

[46] Thomas, M., Lillesand, Kiefer, R. W., Chipman, J. W. (2015): Remote Sensing and Image Interpretation. 7th Ed. - John Wiley \& Sons Incorporation, New York.

[47] Varshney, A. and Rajesh, E. (2014): A comparative study of built-up index approaches for automated extraction of built-up regions from remote sensing data. - Journal of the Indian Society of Remote Sensing 42(3): 659-663.

[48] Xiang, D. L., Tang, T., Hu, C. B., Fan, Q. H., Su, Y. (2016): Built-up area extraction from PolSAR imagery with model-based decomposition and polarimetric coherence. Remote Sensing 8(8): 21.

[49] Xu, H., Lin, D., Tang, F., Wei, C. (2011): Remote sensing of impervious surface dynamics of Xiamen City, southeastern China. - Proceedings of the 19th International Conference on Geoinformatics, 24-26 June, Shanghai, China.

[50] Xu, J., Zhao, Y., Zhong, K., Ruan, H., Liu, X. (2016): Coupling modified linear spectral mixture analysis and soil conservation service curve number (SCS-CN) models to simulate surface runoff: Application to the main Urban Area of Guangzhou, China. Water (Switzerland) 8(12): 550.

[51] Yang, J., Huang, C., Zhang, Z., Wang, L. (2014): The temporal trend of urban green coverage in major Chinese cities between 1990 and 2010. - Urban Forestry and Urban Greening 13(1): 19-27.

[52] Yao, Y., Chen, D., Chen, L., Wang, H., Guan, Q. (2018): A time series of urban extent in China using DSMP/OLS nighttime light data. - PLoS ONE 13(5): 1-24.

[53] Yin, J., Yin, Z., Zhong, H., Xu, S., Hu, X., Wang, J., Wu, J. (2011): Monitoring urban expansion and land use/land cover changes of Shanghai metropolitan area during the transitional economy (1979-2009) in China. - Environmental Monitoring and Assessment 177(1-4): 609-621.

[54] Zhouyu, F., Caelli, T., Nianjun, L., Robles-Kelly, A. (2006): Boosted band ratio feature selection for hyperspectral image classification. - Proceedings of the International Conference on Pattern Recognition. 20-24 August, Hong Kong, pp. 1059-1062. 